\title{
Author Correction: Grain and starch granule morphology in superior and inferior kernels of maize in response to nitrogen
}

\author{
Fucheng Zhao ${ }^{1}$, Liquan Jing ${ }^{2}$, Decheng Wang ${ }^{3}$, Fei Bao ${ }^{1}$, Weiping Lu ${ }^{2}$ \& Guiyue Wang ${ }^{1}$ \\ Correction to: Scientific Reports https://doi.org/10.1038/s41598-018-23977-0, published online 20 April 2018 \\ In the original version of this Article, Guiyue Wang was incorrectly affiliated with 'Jiangsu Hongqi Seed Co., Ltd., \\ Taizhou, Jiangsu, 225300, China' The correct affiliation is listed below.
} Dongyang Institute of Maize Research, Zhejiang Academy of Agricultural Sciences, Dongyang, Zhejiang, 322100,
China.

This error has now been corrected in the PDF and HTML versions of the Article.

(i) Open Access This article is licensed under a Creative Commons Attribution 4.0 International License, which permits use, sharing, adaptation, distribution and reproduction in any medium or format, as long as you give appropriate credit to the original author(s) and the source, provide a link to the Creative Commons license, and indicate if changes were made. The images or other third party material in this article are included in the article's Creative Commons license, unless indicated otherwise in a credit line to the material. If material is not included in the article's Creative Commons license and your intended use is not permitted by statutory regulation or exceeds the permitted use, you will need to obtain permission directly from the copyright holder. To view a copy of this license, visit http://creativecommons.org/licenses/by/4.0/.

(C) The Author(s) 2018

\footnotetext{
${ }^{1}$ Dongyang Institute of Maize Research, Zhejiang Academy of Agricultural Sciences, Dongyang, Zhejiang, 322100, China. ${ }^{2}$ Key Laboratory of Crop Genetics and Physiology of Jiangsu Province, Yangzhou University, Yangzhou, Jiangsu, 225009, China. ${ }^{3}$ Jiangsu Hongqi Seed Co., Ltd., Taizhou, Jiangsu, 225300, China. Correspondence and requests for materials should be addressed to F.Z. (email: Encliff@163.com) or G.W. (email: Zjdygy@163.com)
} 